\title{
Energy-saving House based on the Healthy-Housing theory- in Sanjiangyuan, Qinghai
}

\author{
Zhao Binbin ${ }^{1}$, Chen Yang ${ }^{1 *}$, and Lei Yuhan ${ }^{1}$ \\ ${ }^{1}$ Architecture, Xi'an Jiaotong University, No.28 Xianning West Road, Beilin District, Xi'an, China
}

\begin{abstract}
In view of the real problems of sparse population and relative lying medical conditions in the Sanjiangyuan of Qinghai Province, China, on the basis of studying the passive energy-saving houses in the climate conditions of the area, the Healthy-Housing theory was used to optimize the indoor temperature, humidity, air quality, air circulation and so on. Effectively improving the health comfort of houses in the Sanjiangyuan can reduce the risk of disease-caused by indoor environment, promote residents' health and reduce public medical expenses. This study has provided some help for the construction research in the less developed areas of medical and health conditions.
\end{abstract}

\section{Introduction}

Sanjiangyuan agricultural and pastoral areas belong to the qinghai-Tibet Plateau, due to the high altitude, cold climate, relatively lagging level of public health development, and the population scattered medical inconvenience, resulting in the high mortality rate of the residents of the area, at the same time due to the elevation to the After $3000 \mathrm{~m}$ or more, special geographical climatic factors, such as rising altitude and increased risk of death, have made it difficult to reduce local mortality and public health expenditure.

\subsection{Health risks of Sanjiangyuan}

In Tongren County, Sanjiangyuan, for example, the average life expectancy in the region was 72 years in

Table 1. Main cause of death of the residents of Tongrenxian County, Tongrenxian County, Sanjiang, 2013-2014

\begin{tabular}{|c|c|c|c|c|c|c|c|c|c|}
\hline \multirow{2}{*}{$\begin{array}{l}\text { Disease } \\
\text { Name }\end{array}$} & \multicolumn{3}{|c|}{ Total } & \multicolumn{3}{|c|}{ Male } & \multicolumn{3}{|c|}{ Female } \\
\hline & $\begin{array}{c}\text { Mortality } \\
\text { rate (1 / } \\
100000)\end{array}$ & $\begin{array}{l}\text { Composi } \\
\text { tion }(\%)\end{array}$ & $\begin{array}{c}\text { Alignme } \\
\text { nt }\end{array}$ & $\begin{array}{l}\text { Mortalit } \\
\text { y rate }(1 \\
\text { / 100000) }\end{array}$ & $\begin{array}{l}\text { Composi } \\
\text { tion }(\%)\end{array}$ & $\begin{array}{c}\text { Alignme } \\
\text { nt }\end{array}$ & $\begin{array}{c}\text { Mortalit } \\
\text { y rate }(1 \\
\text { / 100000) }\end{array}$ & $\begin{array}{c}\text { Compositi } \\
\text { on }(\%)\end{array}$ & Alignment \\
\hline Therioma & 141.90 & 23.46 & 1 & 156.97 & 23.73 & 1 & 126.24 & 23.11 & 1 \\
\hline $\begin{array}{c}\text { Cerebrova } \\
\text { scular } \\
\text { disease }\end{array}$ & 103.49 & 17.11 & 2 & 128.71 & 19.46 & 2 & 77.27 & 14.14 & 4 \\
\hline $\begin{array}{l}\text { Disease of } \\
\text { respirator } \\
\text { y system }\end{array}$ & 98.69 & 16.31 & 3 & 96.27 & 14.56 & 3 & 101.21 & 18.53 & 3 \\
\hline $\begin{array}{c}\text { Heart } \\
\text { disease }\end{array}$ & 96.56 & 15.96 & 4 & 88.95 & 13.45 & 4 & 104.47 & 19.12 & 2 \\
\hline $\begin{array}{l}\text { Injury and } \\
\text { poisoning }\end{array}$ & 51.75 & 8.55 & 5 & 70.11 & 10.60 & 5 & 32.65 & 5.98 & 5 \\
\hline
\end{tabular}

(Quoted from: Li Xiaoping, Zhou Minru. Qinghai Tongren County 2013-2014 resident injury cause investigation and analysis)

\footnotetext{
* Corresponding author: 505237108@qq. com
}

2014, lower than the national life expectancy in 201074 . 83 years, also below the average life expectancy of 73 . 08 years in 2014 in Qinghai Province. At the same time, according to the relevant research in the field of medicine, it can be seen that the ranking of malignant tumors, cerebrovascular diseases, respiratory diseases, heart disease and other diseases has become the most important cause of death of residents of Tongren County (Table 1). Therefore, the construction of healthy housing in this area will play an important role in the prevention and control of high-risk chronic diseases such as cardiovascular and respiratory diseases, the improvement of local living environment, the improvement of life expectancy, and the reduction of population mortality and public expenditure. 


\subsection{The value of introducing Healthy-housing theory}

The results of Japanese research show that the indoor environment of building is closely related to human health, such as heart disease, cerebrovascular disease and indoor temperature are significantly related. In Hiroshima Prefecture, Japan, for example, where insulation is more common, the mortality rate from cardiovascular disease in neighbour county decreased significantly by $3.4 \%$ to $9.5 \%$. Japanese scholars put forward the theory of "healthy housing" according to relevant research, which mainly means to achieve the optimal control of "building temperature, humidity, air quality and indoor wind environment" by technical means, improve the comfort of buildings, avoid the health risks caused by the indoor environment of the building, and make residents use the building more comfortably. Longer and healthier, and design means to ensure the energy saving of buildings. In Sanjiangyuan farming and pastoral area, the winter time is long, and heavy snow often blocks the roads, which leads to long indoor activities of residents, and the elderly hardly go out, If there is a long-term health risk in the indoor environment, it will inevitably affect the health of residents, so the theory of healthy housing has an important value for the health and happiness of residents in this area.

\section{Existed houses in Sanjiangyuan}

The theoretical study of healthy housing suggests that room temperature is ideal at $21{ }^{\circ} \mathrm{C}$, while at $18{ }^{\circ} \mathrm{C}$ itis considered to be an allowable temperature, and below $16^{\circ} \mathrm{C}$. Respiratory disease sparingly, and cardiovascular disease if the temperature is as low as $9-12{ }^{\circ} \mathrm{C}$. Based on this, an investigation is made on the existed houses.

\subsection{Basic information of existed housing}

The existed residence adopts $120 \mathrm{~mm}$ red brick as the building material, the room area is small (Fig.1). on the one hand, it is difficult to meet the living area requirements of the traditional herdsman's home for 3-5 people, on the other hand, due to the poor insulation effect of red brick, the indoor living environment quality is not high, and the residents need to use the heated bed for heating for a long time.
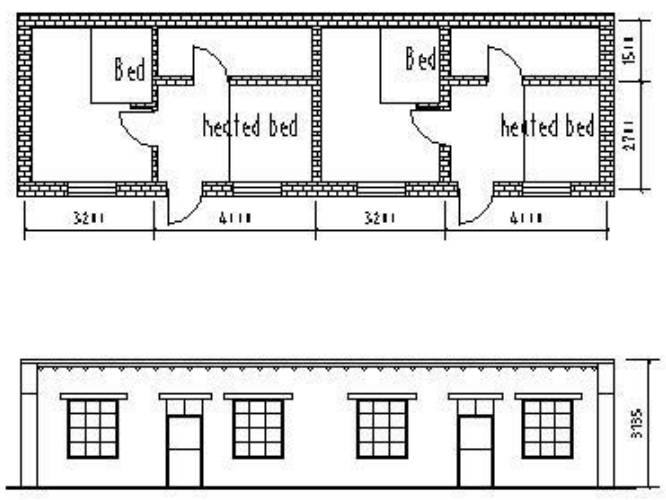

Fig. 1. Plan and elevation of existed house (Author self made)

\subsection{Health risks}

Sanjiangyuan area as a traditional agricultural and pastoral area, local residents used to mainly grazing as the main mode of production, the way of life is water and grass, little settlement, in recent years from grazing to animal husbandry, and thus lack of experience in the construction of settled houses: existed agricultural houses are mainly brick structure of the slope roof form, no insulation layer, at the same time in order to prevent wind, the north wall Do not have window, resulting in poor indoor air quality and circulation, easy to cause odor, even odor and lack of oxygen. Summarize their health risks based on field research as shown in Table 2.

Table 2. Health risks of existed agricultural houses in Mado area (Author self made)

\begin{tabular}{|c|c|c|c|c|c|}
\hline Risk location & Temperature & Humidity & Air quality & Air circulation & Risk \\
\hline Living room & Suitable & \multirow[t]{5}{*}{$\begin{array}{c}\text { Dry, no more than } \\
15 \% .\end{array}$} & Poor, smelly. & Poor & $\begin{array}{c}\text { Respiratory } \\
\text { diseases, hypoxia }\end{array}$ \\
\hline Toilet (outdoor) & $\begin{array}{l}\text { Long periods of } \\
\text { time below } 15^{\circ} \mathrm{C}\end{array}$ & & Normal & Good & \multirow{4}{*}{$\begin{array}{l}\text { Cardiovascular and } \\
\text { cerebrovascular, } \\
\text { respiratory } \\
\text { diseases, outdoor } \\
\text { fractures }\end{array}$} \\
\hline $\begin{array}{l}\text { Access to the toilet } \\
\text { (outdoor) }\end{array}$ & $\begin{array}{l}\text { Long periods of } \\
\text { time below } 15^{\circ} \mathrm{C}\end{array}$ & & Normal & Good & \\
\hline Kitchen & $\begin{array}{l}\text { Long periods of } \\
\text { time below } 15^{\circ} \mathrm{C}\end{array}$ & & Normal & Poor & \\
\hline Hall & Nights below $15^{\circ} \mathrm{C}$ & & Normal & Normal & \\
\hline
\end{tabular}

\section{Optimal design of healthy housing}

According to the requirements of healthy housing theory and research results, set optimization targets: 1. Optimize the room function layout, reduce the frequency of outdoor activities, increase wall heat transfer; 2 . The room's natural room temperature is as high as $16^{\circ} \mathrm{Celsius,}$ which is significantly higher than the performance of existed houses;3. Each room in summer and winter can form an effective and comfortable indoor convective wind, reduce odor, reduce the risk of hypoxia; Make full use of natural light and heat resources, passive energy saving priority; Respect herders accustomed to cooking ghee tea and hot water, by retaining the original habits of artificial heating and humidification, there is no need to add additional systems. 


\section{1. Function optimization}

From the point of view of layout, the existed house is optimized, the main purpose is to reduce the wind speed of the outdoor wind, to ensure the comfort of entering the house, while putting the bathroom indoors to avoid going out to the toilet and increasing the health risk, while making the bedroom located on the left and right sides of the living room, so that the bedroom can make full use of the heat transfer between the walls of the living room heating stove, which increases thermal comfort at night(Fig. 2) .
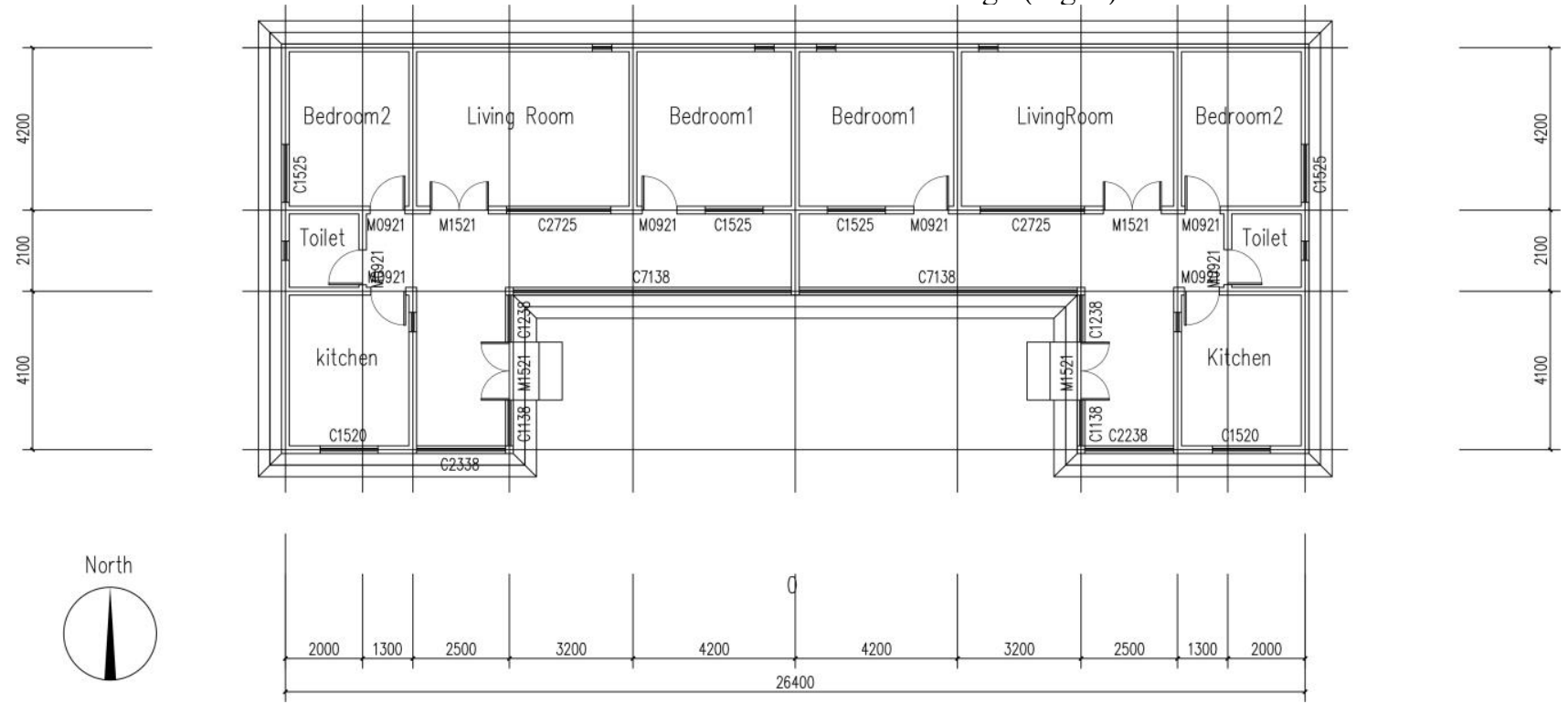

Fig. 2. optimized plan of energy-saving healthy house (Author self made)

\subsection{Wind environment optimization}

Thware is used to simulate indoor and outdoor wind environment to ensure that its indoor and outdoor wind speed in the heating season, meets the needs of human comfort and ensures oxygen supply. In terms of the description of fluids, the fluid model is uncompressible Newtonian fluid, and the turbulence model uses the K$\omega S S T$ model, which is calculated by finite volume. The simulation of the indoor and outdoor wind environment in winter is shown below (Fig. 3), it can be seen that in the inside of the house $1.5 \mathrm{~m}$ height of the air, indoor air has a better circulation, especially in the hall house, fully protect the indoor heating when the oxygen supply demand; The main bedroom and bathroom also become a certain ventilation, to ensure the basic ventilation needs, fresh air. At the entrance to the building, the wind speed is almost reduced to $0 \mathrm{~m} / \mathrm{s}$, ensuring the air environment at the entrance. To simulate maximum ventilation, the wind environment simulation here takes the full open setting of the sash, and the actual wind speed may be lower than the simulated value.

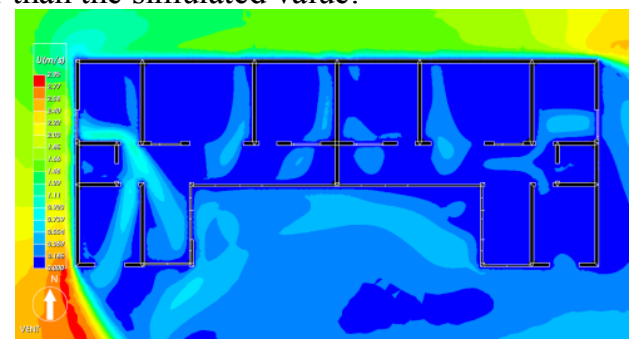

Fig. 3. Typical indoor and outdoor wind velocity cloud in winter (Author self made)

\subsection{Indoor thermal environment optimization}

Indoor thermal comfort is simulated using open source software Dest developed by Tsinghua University. the exterior walls of the building are simulated using ALC concrete (external $30 \mathrm{~mm}, 60 \mathrm{~mm}$ inside) Polyphenyl plate $(60 \mathrm{~mm})$ construction, roof using ALC concrete $(100 \mathrm{~mm})$ with graphite-polyphenyl-plate $(130 \mathrm{~mm})$ construction, the outer window uses Low-e single-frame three-glass aluminum window. Optimized, the most rooms have natural room temperature simulation results near or or more than $70 \%$ of the total annual time at more than $16^{\circ} \mathrm{C}$ (Fig. 4), $\mathrm{XXX}$ is improved compared to the pre-optimization effect. Herders only need to use stoves for heating, boiling water and cooking in the hall house to maintain indoor heat comfort for a long time and improve indoor humidity, while greatly reducing the health risks due to going out to the toilet, especially the elderly health risks.

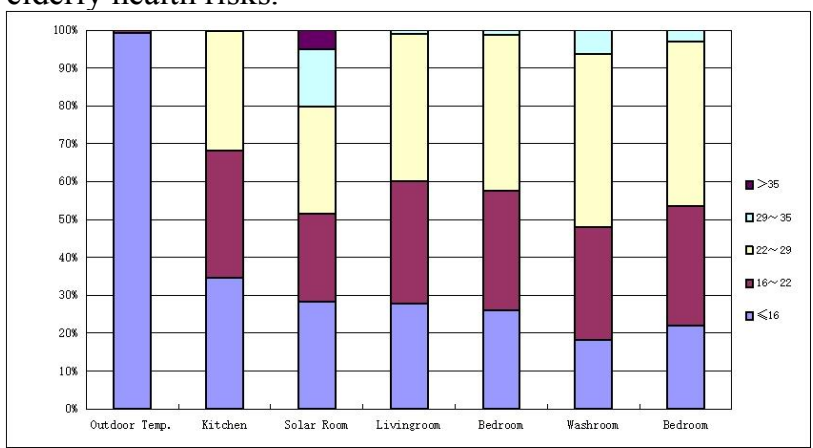

Fig. 4. Statistical distribution of natural and outdoor temperature in each room (Author self made) 


\section{Conclusion}

According to the theory of healthy housing, the study analyzes the existed houses, from the perspective of indoor and outdoor wind environment, indoor thermal comfort, the existed houses has been effectively optimized, so that residents are exposed to unhealthy indoor environment risk greatly reduced, compared to existed houses: almost eliminating residents to enter or leave the houses. Wind environment risk, improve indoor air circulation efficiency, reduce the risk of hypoxia. The new ALC concrete with graphitepolyphenyl-plate exterior wall and the structural system of the light steel keel frame have greatly improved the insulation effect of the enclosure structure, taking into account the requirements of the short construction cycle due to the cold climate, the building capping cycle is approximately 1 week. The study reduced the health risk of existed houses in Sanjiangyuan area from a number of environmental factors, effectively improved the quality of local people's living environment, and provided support for the health of farmers and herdsmen in Sanjiangyuan area, which has high promotional value.

\section{Acknowledgement}

This paper is supported by the project "Research on energy use system of Sanjiangyuan agricultural and pastoral area, Qinghai Province (2018-s-5)"

\section{References}

1. Huang Yuma, Analysis of the characteristics of the Tibetan population in Qinghai, Qinghai Ethnic Studies, 03(2000)

2. Masao Ta, Wang, A brief analysis of the mortality characteristics of the population in the QinghaiTibet Plateau, Qinghai Technology, 11(2004)

3. Li Xiaoping, Zhou Minru, Tongren County, Qinghai 2013-2014 Investigation and analysis of the cause of death of sick and injured residents in the year, Medical animal defense, 33(2017)

4. Hirofumi Hayama , Yuki Kamazawa , Understanding the actual condition of changes in the living environment on the body: Part 1 Disease occurrence and construction timing and structural analysis of houses nationwide, Other (2011)

5. Ministry of Health, Labour and Welfare. https:/www. mhlw. go. jp/toukei/saikin/hw/jinkou/kakutei14/index. html, 2014. 